\title{
A Comparison of Online and Hybrid Professional Development for CS Principles Teachers
}

\author{
Jennifer Rosato \\ College of St. Scholastica \\ 1200 Kenwood Ave \\ Duluth, MN \\ 1 (218) 723-6000 \\ jrosato@css.edu
}

\author{
Chery Lucarelli \\ College of St. Scholastica \\ 1200 Kenwood Ave \\ Duluth, MN \\ 1 (218) 723-6000 \\ clucarelli@css.edu
}

\author{
Cassandra Beckworth \\ College of St. Scholastica \\ 1200 Kenwood Ave \\ Duluth, MN \\ $1(218) 723-6000$ \\ cbeckworth@css.edu
}

\author{
Ralph Morelli \\ Trinity College \\ 300 Summit St \\ Hartford, CT \\ 1 (860) 297-2220 \\ ralph.morelli@ \\ trinitycollege.edu
}

\begin{abstract}
The College of St. Scholastica, in partnership with Trinity College, adapted the Mobile Computer Science Principles (CSP) curriculum and professional development (PD) for delivery online to reach high school teachers unable to attend traditional face-toface PD. The Mobile CSP curriculum and PD were designed to increase the number of schools offering computer science (CS) courses and to broaden the participation of traditionally underrepresented students such as females and minorities. A deliberate and intentional process was used that incorporates evidence-based practices for the online environment and professional development. A comparison of student and teacher results suggests that online PD can be a successful strategy for scaling computer science professional development. This paper will discuss not only these results but also challenges from the first year of the project and how they are being addressed in subsequent years. This report focuses primarily on the activities and accomplishments of the online PD, although data and accomplishments are provided for the Mobile CSP project as a whole where appropriate.
\end{abstract}

\section{CCS Concepts}

Social and professional topics $\rightarrow$ Computing education; Computer science education; K-12 education

\section{Keywords}

Computer science principles; K-12 computer science; online professional development; community of practice

\section{INTRODUCTION}

The project is one of several $\mathrm{CS} 10 \mathrm{~K}$ projects funded by the National Science Foundation (NSF) in an effort to broaden participation of underrepresented groups in computing by increasing the number of computer science (CS) course offerings at the high school level in the United States [10]. Mobile CSP includes two main efforts to support broadening participation: (1) curriculum development for the College Board's Advanced Placement CS Principles (CSP) course, which will offer its first

Permission to make digital or hard copies of all or part of this work for personal or classroom use is granted without fee provided that copies are not made or distributed for profit or commercial advantage and that copies bear this notice and the full citation on the first page. Copyrights for components of this work owned by others than the author(s) must be honored. Abstracting with credit is permitted. To copy otherwise, or republish, to post on servers or to redistribute to lists, requires prior specific permission and/or a fee. Request permissions from Permissions@acm.org.

ITiCSE '17, July 03-05, 2017, Bologna, Italy

Copyright is held by the owner/author(s). Publication rights licensed to

ACM. ACM 978-1-4503-4704-4/17/07 ...\$15.00

DOI: http://dx.doi.org/10.1145/3059009.305906
Advanced Placement (AP) exam in May 2017; and (2) training and professional development (PD) for high school teachers. In addition to being funded by the NSF, Mobile CSP is one of several courses endorsed by the College Board. The PD is open to teachers from all academic disciplines, a necessity, due to the serious lack of teachers in the United States who are trained and certified to teach a high school computer science course [8].

There are a number of confounding factors that have created a lack of well-prepared CS teachers in the United States. Many educational leaders and government agencies have not recognized $\mathrm{CS}$ as a required content area, relegating this to an elective course in most high schools. Despite the fact that 9 out of 10 parents want their students to have exposure to CS courses, fewer than $25 \%$ of high schools offer CS [8]. The Computer Science Teachers Association [2], in its report on the status of teacher certification in CS, "Bugs in the System," highlights the United States confusing CS teacher certification process that varies widely from state to state. For example, in most states, teachers need to obtain a teaching license in another content area before they can gain certification in CS. Other states forego this process and do not require any CS certification requirement outside of the teacher holding a valid teaching license. The lack of well-prepared teachers and the lack of recognition for CS as a content area on par with other areas such as math and English has contributed to the shortage of certified and well-prepared CS teachers [2].

In addressing the teacher shortage, NSF has called out the need to scale up CS teacher PD, focusing in particular on the further development of online teacher PD. As Cuny [4] noted, the United States is far short of its original goal to train 10,000 teachers, yet there is growing interest in CS education. Online PD provides the scalability that is needed to address this challenge [4], offering not only cost saving measures, but also providing flexible options to meet the needs of teachers' personal lives. Additionally, teachers in rural locations may find that PD formats that require onsite attendance create accessibility barriers that cannot be overcome. Online PD can also address the isolation factor that many CS teachers face. According to the CS10K Common Data Elements Evaluation Working Group (EWG) Year 1 Project Report (R. Zarch \& T, McKlin, personal communication, January 6, 2016), smaller and more rural schools are less likely to offer CS courses. Their teachers are more likely to be the only CS teacher and as such are eager for opportunities to discuss their courses and teaching with peers. Even teachers in larger schools that are just beginning to offer CS may suffer from the same sense of isolation. The CS Education Landscape study calls for CS PD that can address teachers who are isolated or difficult to reach as the 
majority of current PD offerings are in person with less than half of those providing online PD [1].

\subsection{Professional Development}

Effective teacher professional development includes several critical characteristics. Hardee's [9] meta-analysis of teacher PD as well as other effective practices suggested by the research have framed the Mobile CSP professional development. According to Hardee [9], the five guiding principles of effective PD include: 1) Long term and intensive professional development rather than short-term workshops; 2) Clear outcomes that prioritize the PD; 3) Collaborative and reflective learning communities; 4) PD that embraces online technology tools; 5) Five core features that include pedagogical content knowledge, incorporation of standards and policies, active learning, mentoring and individual learning (see Table 1). These guiding principles are also supported by the research of Darling-Hammond, Wei, Andree, Richardson, \& Orphanos [5] who suggest in their meta-analysis that PD should be intensive, lasting at least 50 hours on a given topic, and ongoing, spanning six to 12 months. This critical component is also supported by the Landscape study [1] which recommends that CS PD include more contact over longer periods of time (e.g. ongoing support during the academic year). Additionally, DarlingHammond et al. [5] noted that when teacher PD is part of a study group with mentoring, the potential for significant and positive change to teacher practices increases. The study also reports that effective PD should focus on the specific subject matter that is tied to classroom practices. Mobile CSP has worked to implement these guiding principles as shown in Table 1.

As stated earlier, the research on effective teacher PD calls out the importance of creating a sense of community with participants and to ultimately work towards a "community of practice". As defined by Wenger-Trayner, B., \& Wenger-Trayner, T. [12] "Communities of practice are groups of people who share a concern or a passion for something they do and learn how to do it better as they interact regularly" (para. 5). Communities of practice have three critical components: 1) A commitment to the domain (a shared interest in the subject matter); 2) Community individuals who engage in activities together, building relationships to learn together; 3) Practice - Communities of practice include practitioners who learn together to improve their practice [12]. Communities of practice support the goals of schools and educational professionals, and many schools have formal structures to support the learning goals of teachers called, professional learning communities (PLC) which focus on teaching practices and student learning goals [6].

\subsection{Online Learning}

The Mobile CSP project structures its PD around evidence-based principles that are grounded in research. Scaling the PD by offering the program online requires intentional and deliberate implementation choices to ensure that the critical components of the PD are incorporated. This approach to online learning is based on the Community of Inquiry Model or CoI [7], which reinforces the idea of establishing strong learning communities that include collaboration and reflection for improved understanding of course content. The model suggests that there are three elements in the online learning environment that need to be addressed: social presence, cognitive presence, and teaching presence.

Garrison et al. [7], note that social presence allows participants in the online environment to have a sense of self and belonging and to present themselves as "real people." Teaching presence is the idea that teachers must do more than merely provide instructional materials; instead, teachers must facilitate social engagement so that students have opportunities to create real meaning from the material. Finally, cognitive presence is the process of constructing knowledge and meaning through collaborative reflection and inquiry.

The specific components of the Mobile CSP PD are described in the next section and outlined in Table 2. These components are aligned and supported by research in effective PD.

\section{METHODOLOGY}

The Mobile CSP course is one of several courses endorsed by the College Board and includes a complete off-the-shelf implementation of the CSP framework [3]. Mobile CSP has a unique focus on mobile app development: students learn the principles of computer science by creating "socially useful" mobile apps - apps, broadly speaking, that matter to them and their community in their everyday lives. In addition to programming and CS principles, the course is project-based and emphasizes writing, communication, collaboration, and creativity. The course content is hosted online on a Google Course Builder platform that consists of two branches: (1) a student-facing branch, designed to be used by teachers in the classroom; and (2) a parallel teacher-facing branch that contains lessons plans, assessments, and other resources used by teachers. In particular, it provides opportunities for critical reflection during the PD, background on evidence-based pedagogy, a focus on recruiting and retaining underrepresented populations, and other content to help support the teaching of Mobile CSP.

The project's PD is currently offered in a 4-week summer course that can be taken in two formats: completely online within cohorts of approximately ten teachers or in a hybrid format (part online and part in-person) within a regional cohort of other teachers.

Table 1. Implementation of Effective PD Practices

\begin{tabular}{|l|l|}
\hline \multicolumn{1}{|c|}{ PD Practice } & Implementation \\
\hline $\begin{array}{l}\text { Long-term and } \\
\text { intensive }\end{array}$ & $\begin{array}{l}\text { 4-week summer course with ongoing } \\
\text { academic year support }\end{array}$ \\
\hline $\begin{array}{l}\text { Outcomes clearly } \\
\text { defined }\end{array}$ & $\begin{array}{l}\text { Shared and reinforced with participants in } \\
\text { application, webinars, master teacher } \\
\text { training }\end{array}$ \\
\hline $\begin{array}{l}\text { Supports } \\
\text { communities of } \\
\text { teachers }\end{array}$ & $\begin{array}{l}\text { 10-12 teachers with a master teacher, who } \\
\text { uses presentations, emails, and video } \\
\text { conferences to provide support and } \\
\text { encourage engagement }\end{array}$ \\
\hline $\begin{array}{l}\text { Online tools } \\
\text { implemented }\end{array}$ & $\begin{array}{l}\text { Video conferences, discussion forums, } \\
\text { video recordings, and online portfolios }\end{array}$ \\
\hline $\begin{array}{l}\text { 5 Core features: 1) } \\
\text { pedagogy, 2) } \\
\text { standards, 3) active } \\
\text { learning, 4) } \\
\text { mentoring, 5) } \\
\text { individual learning }\end{array}$ & $\begin{array}{l}\text { 1) CSP framework and CSTA standards; 2) } \\
\text { a review of CS education policy and reform } \\
\text { efforts; 3) master teachers; 4) individual } \\
\text { projects; and 5) active learning through } \\
\text { discussions, Google Hangouts, and course } \\
\text { materials }\end{array}$ \\
\hline
\end{tabular}

The professional development components, described in more detail below, support the CoI model by reinforcing teacher, social, and cognitive presence as follows. 
Table 2. Community of Inquiry (COI) Model in Mobile CSP

\begin{tabular}{|l|c|c|c|}
\hline & $\begin{array}{c}\text { Teacher } \\
\text { Presence }\end{array}$ & $\begin{array}{c}\text { Social } \\
\text { Presence }\end{array}$ & $\begin{array}{c}\text { Cognitive } \\
\text { Presence }\end{array}$ \\
\hline Student Branch Lessons & $\mathrm{X}$ & & $\mathrm{X}$ \\
\hline Teach Branch Lessons & $\mathrm{X}$ & & $\mathrm{X}$ \\
\hline Discussion Forum & & $\mathrm{X}$ & $\mathrm{X}$ \\
\hline Master Teacher Hangouts & & $\mathrm{X}$ & $\mathrm{X}$ \\
\hline Project Support Websites & $\mathrm{X}$ & & \\
\hline Webinars & $\mathrm{X}$ & $\mathrm{X}$ & $\mathrm{X}$ \\
\hline Video Reflection Task & & $\mathrm{X}$ & $\mathrm{X}$ \\
\hline
\end{tabular}

\subsection{Professional Development Components}

\subsubsection{Master Teachers}

Master teachers aim to support, manage, motivate, and facilitate community amongst their assigned PLC. Master teachers have successfully taught Mobile CSP at least once, demonstrated an aptitude for online communication, and displayed a growth mindset towards those with little to no previous experience teaching CS. Before beginning their role, master teachers complete an in-person orientation that includes information on online learning, coaching, adult learners, stereotype threat, and cooperative learning. Master teachers also participate in a PLC throughout the PD and academic year. Master teachers are provided with an online discussion forum, resource website, and periodic video conferences that aim to discuss issues they may face when mentoring. Master teachers assist the project team in tracking teacher participation and completion of project requirements, especially during the summer PD.

\subsubsection{Summer \& Academic Year PD}

During the summer PD, participating teachers complete a majority of the student lessons and assessments, review lesson plans, and reflect on the CSP concepts, practices, and pedagogical strategies. Following the requirements for the AP exam their students will undergo during the academic year, teachers complete the Create Performance Task (PT) and final exam, as well as review student samples for the Explore PT. The Create PT requires learners to work collaboratively to develop a mobile app. The Explore PT requires that learners work independently to research the societal impact of computing innovations related to mobile apps. Learners must complete a practice and final assignment for each PT. In addition to completing the PTs, teachers also complete a pre- and post-PD survey and meet with their PLC and master teacher via online video conferencing software once a week. While teachers are only required to attend one PLC meeting a week, they often attend two. In the academic year, participants teach the full curriculum, meet monthly with their PLC, complete pre- and postacademic year surveys, complete a video reflection task twice a year, and assist in collecting student data. Student data collected includes pre- and post-surveys, midterm, final exam, and PTs. Additional academic year support is provided to teachers in the form of a discussion forum, which is accessible to the entire Mobile CSP community, and optional monthly webinars hosted by Mobile CSP staff.

\subsubsection{Project Support Websites}

Three comprehensive support websites were created to provide support and communication avenues for participants and master teachers. The Master Teacher Resource website serves as a resource to aid master teachers in facilitating community with their assigned PLC. Teachers have access to a Teacher Resource and a Video Task Reflection website. Both serve to provide resources as well as tutorials to support project requirements.

\subsubsection{Webinars}

During the summer professional development, weekly webinars are hosted by the project team to provide a clear message on the project's goals and processes as well as provide an opportunity for reinforcement of key concepts. During the academic year, webinars are held less frequently on a quarterly to monthly basis but with a similar purpose - reinforcing project goals and processes and providing just-in-time professional development. Topics include active recruiting, PT overview, technical writing, and various pedagogical strategies.

\subsubsection{Video Reflection Task}

During the academic year, teachers are required to record video of their classroom, write a reflection, and discuss the videos of other PLC members. The video reflection task is supported by research in teacher professional development. Darling-Hammond et al. [5] noted that an important part of addressing isolation and improving teaching practice is to have teachers observe each other, providing ideas for improvement. The task provides teachers an opportunity to reflect on their teaching as well as conduct a virtual visit to another CS teacher's classroom. Darling-Hammond et al. [5] suggest that teachers may want to use videos of themselves teaching to share their practices and to watch other teachers teach and that by doing so are more likely to positively change their teaching practices. Tripp \& Rich [11] emphasized the importance of guided reflection when teachers view and reflect on their own teaching through video. They also noted that teachers found the sharing of their reflections after watching themselves teach most meaningful when there was an opportunity to collaborate with other educational professionals. Most importantly, Tripp and Rich [11], shared that several studies support the positive impact on teacher change that may occur when teachers use video to reflect on their own teaching. In our project, teachers are sharing their videos of themselves teaching with their assigned PLC, connecting virtually from all areas of the United States.

\subsection{Hybrid PD Model Differences}

During the summer PD, the hybrid teachers met two of the four weeks face-to-face with the online weeks including daily checkins using video conferencing. During the academic year, the hybrid and online teachers are provided similar supports, although hybrid teachers are not required to complete the video reflection task. Hybrid teachers did not have access to the teacher and master teacher resource websites, either. Finally, all of the hybrid locations included a pair of facilitators - a master teacher and a college or university CS professor.

\section{RESULTS \& DISCUSSION}

Overall, the data show that the online PD has been successful and its students and teachers display similar results to those that participated in the hybrid PD. The Mobile CSP project offered online PD in summer 2015 and 2016, while the hybrid PD has been in place for two additional years (2013 and 2014). The hybrid and online PD used a common application form in which teachers could specify the format of the PD they were willing to attend. In 2015-16, teachers were required to select either hybrid or online. In $2016-17$, almost half $(49 \%, \mathrm{~N}=251)$ selected online $\mathrm{PD}$, while another $29 \%(\mathrm{~N}=150)$ selected either online or hybrid. 
Overwhelmingly, teachers are willing and interested in participating in online PD offerings.

Table 3 below illustrates the number of teachers who were trained in the online and hybrid programs. Stipends for completing the PD were available in all years. Hybrid teachers have received $\$ 1,000 /$ week of PD each year, while online teachers received $\$ 1,000$ for $2015-16$ and up to $\$ 4,000$ for $2016-17$, a potential factor in PD completion rates.

Table 3. PD Completion Data

\begin{tabular}{|l|l|l|l|l|}
\hline \multirow{2}{*}{} & \multicolumn{2}{|c|}{ 2015-16 } & \multicolumn{2}{c|}{ 2016-17 } \\
\cline { 2 - 5 } & \multicolumn{1}{|c|}{ Hybrid } & Online & Hybrid & Online \\
\hline $\begin{array}{l}\text { Accepted to } \\
\text { participate in } P D\end{array}$ & $\mathrm{~N}=12$ & $\mathrm{~N}=42$ & $\mathrm{~N}=98$ & $\mathrm{~N}=117$ \\
\hline $\begin{array}{l}\text { Actual Trained } \\
\text { (Completed } P D)\end{array}$ & $\begin{array}{l}100.00 \% \\
\mathrm{~N}=12\end{array}$ & $\begin{array}{l}45.24 \% \\
\mathrm{~N}=19\end{array}$ & $\begin{array}{l}96.94 \% \\
\mathrm{~N}=95\end{array}$ & $\begin{array}{l}88.03 \% \\
\mathrm{~N}=103 *\end{array}$ \\
\hline
\end{tabular}

* Note that 6 online participants dropped out before the program began, 5 dropped out during the PD, and 3 did not successfully complete PD requirements.

The online Mobile CSP PD serves teachers in more schools identified as rural than overall $\mathrm{CS} 10 \mathrm{~K}$ project statistics and national school data (Table 4). According to the CS10K Common Data Elements EWG Year 1 Project Report, online PD has also been able to reach teachers in states not served in other years, including Alaska and Hawaii (R. Zarch \& T, McKlin, personal communication, January 6, 2016).

Table 4. "Urbanicity" of Schools Served

\begin{tabular}{|c|c|c|c|c|}
\hline & \multicolumn{2}{|c|}{ 2014-15 } & 2015-16* & 2016-17** \\
\hline & National $* * *$ & $\begin{array}{c}\text { CS10K } \\
\text { Projects }\end{array}$ & $\begin{array}{c}\text { Mobile CSP } \\
\text { Online }\end{array}$ & $\begin{array}{c}\text { Mobile CSP } \\
\text { Online }\end{array}$ \\
\hline City & $27 \%$ & $33 \%$ & $\begin{array}{r}22.73 \% \\
\mathrm{~N}=5\end{array}$ & $\begin{array}{r}31.96 \% \\
\mathrm{~N}=31\end{array}$ \\
\hline Suburb & $31 \%$ & $41 \%$ & $\begin{array}{r}36.36 \% \\
\mathrm{~N}=8\end{array}$ & $\begin{array}{r}27.84 \% \\
\mathrm{~N}=27 \\
\end{array}$ \\
\hline Town & $14 \%$ & $11 \%$ & $\begin{array}{r}9.09 \% \\
\mathrm{~N}=2 \\
\end{array}$ & $\begin{array}{r}12.37 \% \\
\mathrm{~N}=12 \\
\end{array}$ \\
\hline Rural & $28 \%$ & $13 \%$ & $\begin{array}{r}31.82 \% \\
\mathrm{~N}=7 \\
\end{array}$ & $\begin{array}{r}27.84 \% \\
\mathrm{~N}=27 \\
\end{array}$ \\
\hline Total & & & $\begin{array}{l}100 \% \\
\mathrm{~N}=22\end{array}$ & $\begin{array}{l}100 \% \\
\mathrm{~N}=97\end{array}$ \\
\hline
\end{tabular}

* Only 22 of the 42 total accepted 2015-16 participants' schools had National Center of Education (NCES) statistics available.

** Only 97 of the 117 total 2016-17 participants' schools had NCES statistics available.

*** National data on United States public school designation

\subsection{Teacher Data}

\subsubsection{Teacher Demographics}

Overall, the teachers in both the hybrid and online PD have similar backgrounds and experience levels in CS. Teachers in the hybrid PD have taught on average 9.42 years $(2015-16)$ and 12.84 (2016-17), similar to teachers in the online PD, 10.63 years (201516) and 12.88 (2016-17). While teachers in both the hybrid and online PD are primarily STEM (science, technology, engineering, and math) teachers, both formats include teachers from other backgrounds (see Table 5).

In $2016,43 \%$ of teachers reported that they are currently teaching computer science, which represents an increase over previous years. Approximately $20 \%$ of this year's teachers reported that they had a degree in computer science and another 32\% reported having taken $\mathrm{CS}$ courses in college. Regarding programming experience, $58 \%$ of teachers identified themselves as "beginners" $(16 \%)$ or as having a little experience $(42 \%)$.

Table 5. Teacher Certification and Subjects Taught

\begin{tabular}{|l|r|r|r|r|}
\hline & \multicolumn{2}{|c|}{ Certification } & \multicolumn{2}{c|}{ Subjects Taught } \\
\cline { 2 - 5 } & Hybrid & Online & Hybrid & Online \\
\hline Science, Engineering, Math & 63 & 62 & 53 & 49 \\
\hline Computer Science & 21 & 44 & 77 & 87 \\
\hline Business/Career Tech Ed & 35 & 71 & 35 & 64 \\
\hline All Other Subjects & 14 & 24 & 4 & 8 \\
\hline
\end{tabular}

\subsubsection{Teacher CS Knowledge and Attitudes}

Teachers in both the online and hybrid PD performed similarly on the common final exam. The final exam assessed CS content knowledge and mirrors the final assessment that students take at the end of the academic year. In the first year of the project, hybrid teachers on average received a score of $88 \% \quad(\mathrm{~N}=12)$ whereas the online participants received a score of $90 \%(\mathrm{~N}=29)$. In the second year of the project, hybrid teachers received average scores of $82 \%(\mathrm{~N}=93)$ and online teachers of $83 \%(\mathrm{~N}=94)$. The overall lower score in Year 2 could be a result of the shortened PD (4 instead of 6 weeks), which did not cover some topics in the same depth and covered only a small portion of the data unit.

When asked to respond to the statement, "Teaching CS is highly appealing to me," $99 \%$ of online teachers $(\mathrm{N}=111)$ and $100 \%$ of hybrid teachers $(\mathrm{N}=87)$ replied strongly agree or agree on a standard 5 point Likert scale. Teacher attitudes towards CS, in general, were also positive and similar for both PD formats as shown Table 6.

Table 6. Computer Science Attitudes

\begin{tabular}{|l|c|c|c|c|}
\hline & \multicolumn{2}{|c|}{ Hybrid } & \multicolumn{2}{c|}{ Online } \\
\hline & $\begin{array}{c}\mathbf{2 0 1 5} \\
\mathbf{1 6}\end{array}$ & $\begin{array}{c}\mathbf{2 0 1 6} \\
\mathbf{1 7}\end{array}$ & $\begin{array}{c}\mathbf{2 0 1 5} \\
\mathbf{1 6}\end{array}$ & $\begin{array}{c}\mathbf{2 0 1 6} \\
\mathbf{1 7}\end{array}$ \\
\hline $\begin{array}{l}\text { This course improved my } \\
\text { understanding of computer } \\
\text { science. }\end{array}$ & 3.75 & 3.43 & 3.42 & 3.37 \\
\hline $\begin{array}{l}\text { I learned that I have more } \\
\text { programming talent than I was } \\
\text { aware of. }\end{array}$ & 3.09 & 2.80 & 2.84 & 2.80 \\
\hline $\begin{array}{l}\text { I have become more interested in } \\
\text { computer science. }\end{array}$ & 3.75 & 3.40 & 3.11 & 3.26 \\
\hline $\begin{array}{l}\text { Computer science is a socially } \\
\text { beneficial discipline. }\end{array}$ & 3.67 & 3.68 & 3.67 & 3.83 \\
\hline $\begin{array}{l}\text { Four point scale 1-Not at all true; 2-Somewhat true; 3-Quite true; } \\
\text { 4-Completely true }\end{array}$ & & & \\
\hline
\end{tabular}




\subsubsection{Teacher PD Attitudes}

Overall, in both years 1 and 2 of the project, teachers seemed to view the PD very positively. On average, teachers in both the hybrid and online projects tended to agree or strongly agree that they enjoyed the PD (see Table 7). Furthermore, in regards to year 2 data, $95.50 \%$ of online teachers $(\mathrm{N}=106)$ and $95.40 \%$ of hybrid teachers $(\mathrm{N}=82)$ identified that they felt generally to very confident that their Mobile CSP course would go well after participating in the 2016-17 PD.

In addition to enjoying the PD, teachers were also asked to evaluate whether or not they felt the training activities fostered a sense of community among participants. As noted in Table 7 below, hybrid teachers, on average, in both the 2015-16 and 201617 projects, tended to choose "agree" and "strongly agree" that the PD activities encouraged community among their cohort members. This figure is slightly less for online teachers who trend lower on the scale and tend to agree to this statement measuring community (see above). The higher average for the hybrid program aligns with expectations; those who have an opportunity to meet with others in their cohort face-to-face would be expected to feel a stronger sense of community among participants than those who do not have an opportunity to meet others in-person (online project). In Table 8 below the community component is explored further in the 2016-17 project as teachers were asked to identify the specific PD course activities that they felt fostered a sense of community.

Table 7. PD Attitudes

\begin{tabular}{|l|r|r|r|c|}
\hline & \multicolumn{2}{|c|}{ Hybrid } & \multicolumn{2}{c|}{ Online } \\
\hline & $\mathbf{2 0 1 5 - 1 6}$ & $\mathbf{2 0 1 6 - 1 7}$ & $\begin{array}{c}\mathbf{2 0 1 5} \\
\mathbf{1 6}\end{array}$ & $\begin{array}{c}\mathbf{2 0 1 6} \\
\mathbf{1 7}\end{array}$ \\
\hline $\begin{array}{l}\text { I have enjoyed this professional } \\
\text { development course }\end{array}$ & 4.67 & 4.58 & 4.37 & 4.51 \\
\hline $\begin{array}{l}\text { Training activities fostered a } \\
\text { sense of community among the } \\
\text { participants }\end{array}$ & 4.42 & 4.49 & 3.67 & 3.79 \\
\hline
\end{tabular}

Five point scale 1-Strongly Disagree, 2-Disagree, 3-Neutral, 4Agree, 5-Strongly Agree

Table 8. Community Supporting Activities

\begin{tabular}{|l|r|r|}
\hline \multirow{2}{*}{} & \multicolumn{2}{|c|}{$\mathbf{2 0 1 6 - 1 7}$} \\
\cline { 2 - 3 } & Hybrid & \multicolumn{1}{c|}{ Online } \\
\hline Narrated video content & 3.14 & 3.05 \\
\hline Mentor Groups & 3.42 & 3.13 \\
\hline Google Hangouts & 2.85 & 3.12 \\
\hline Discussion Forums & 2.60 & 2.43 \\
\hline Online Office Hours & 2.85 & 2.75 \\
\hline In-person classroom sessions & 3.71 & 3.29 \\
\hline Other & 3.29 & 3.67 \\
\hline Averag & & \\
\hline
\end{tabular}

Averages are based on a 4 point Likert scale: 4-Very Helpful, 3-

Somewhat Helpful, 2-Helpful, 1-Not at all Helpful.

Overall, hybrid and online participants found the majority of the PD course activities to be somewhat to very helpful. However, there are some discrepancies that are important to note. Some of the PD course activities that are listed, such as an opportunity to meet in-person, were not offered to online participants. While those in the online project tended to identify "in-person classroom sessions" as being somewhat to very helpful (average of 3.29), this activity was unavailable to online participating teachers. We believe that teachers may have mistaken the "in-person sessions" for the required weekly virtual meetings with their mentors or personal one-on-one communications with project team members. Additionally, this section of questions did not offer a "Not Applicable" option. For the 2017-18 project, we have implemented changes to our surveys and assessments to ensure that all questions and categories are clearly defined as well as provide a "Not Applicable" option where appropriate.

\subsection{Student Data}

Table 9 summarizes student participation over the four years of the project. Only teachers and students who have shared student data with the project are included in the table. Table 10 provides an aggregate summary of student demographics over all four years of the project, including students served by both online and hybrid teachers. For the first time this year, the combined percentage of underrepresented minorities (URMs) and females has exceeded $50 \%$. At the time of writing this paper, only student assessment data for 2015-16 was available. Students with teachers in the hybrid and online PD performed similarly on summative assessments (Table 11). Student attitudes towards the course and computer science were also positive (Table 12).

Table 9. Student Enrollments

\begin{tabular}{|l|r|r|r|r|}
\hline & $\mathbf{2 0 1 3 - 1 4}$ & $\mathbf{2 0 1 4 - 1 5}$ & $\mathbf{2 0 1 5 - 1 6}$ & 2016-17* \\
\hline Hybrid & 330 & 648 & 554 & 2,280 \\
\hline Online & - & - & 242 & 2,129 \\
\hline TOTALS & 330 & 648 & 748 & 4,409 \\
\hline * Does not account for courses with a spring semester start date. \\
\hline
\end{tabular}

Table 10. Project-wide Student Demographics

\begin{tabular}{|l|r|r|r|r|}
\hline & $\mathbf{2 0 1 3 - 1 4 *}$ & $\mathbf{2 0 1 4 - 1 5 *}$ & $\mathbf{2 0 1 5 - 1 6}$ & $\mathbf{2 0 1 6 - 1 7}$ \\
\hline Males & $77.16 \%$ & $71.12 \%$ & $78.05 \%$ & $71.86 \%$ \\
\hline Females & $22.84 \%$ & $28.88 \%$ & $21.95 \%$ & $28.14 \%$ \\
\hline URM & $31.69 \%$ & $34.14 \%$ & $21.62 \%$ & $33.34 \%$ \\
\hline URM or Female & $43.61 \%$ & $49.67 \%$ & $38.77 \%$ & $50.72 \%$ \\
\hline *Hybrid only data & & \\
\hline
\end{tabular}

Table 11. Student Summative Assessment Averages

\begin{tabular}{|l|r|r|r|}
\hline & \multicolumn{2}{|c|}{ Hybrid } & Online \\
\hline & $\mathbf{2 0 1 4 - 1 5}$ & $\mathbf{2 0 1 5}-16$ & $\mathbf{2 0 1 5 - 1 6}$ \\
\hline Explore PT & 70.5 & 78.1 & 82.7 \\
\hline Create PT & 76.5 & 74.7 & 84.6 \\
\hline Final Exam & 71.0 & 71.0 & 72.1 \\
\hline
\end{tabular}

Table 12. Percent of students agreeing with statements about the course and CS (2015-16)

\begin{tabular}{|l|l|}
\hline I enjoyed this class. & $72 \%$ \\
\hline I will probably take more CS courses after this one. & $64 \%$ \\
\hline
\end{tabular}


I might major in Computer Science.

\begin{tabular}{|l|l|}
\hline Computer science is intellectually deep and challenging. & $79 \%$ \\
\hline
\end{tabular}

\subsection{Lessons Learned from Year 1}

During the first year of the online PD, we encountered three significant challenges: 1) master teacher expectations for participant support; 2) consistent support from project staff; and 3) misunderstanding of program and curriculum requirements. Some of the challenges with master teachers were due to personal life events or lack of follow through on expectations. To better address expectations, in the second year of the project, a more detailed master teacher job description, application process, and two days of onsite orientation were implemented.

Secondly, during the first grant year, the project team hired a parttime staff member, who also had separate full-time employment. The part-time hours were not sufficient, making it difficult to address the communication and support needs of the participants. In the second year, the position was changed to full-time, providing consistent, high-quality support and communication. The staff member also conducted individual phone calls with each accepted participant and started a monthly newsletter.

Some participating teachers conveyed misunderstanding of program and curriculum requirements including technical difficulties. We believe that many of the difficulties were due to teachers not fully understanding the necessary technical components that were needed for the successful implementation of the curriculum (e.g. student access to Wi-Fi, student Google accounts, and availability of mobile Android devices).

To better address the technical issues in year 2, the project website was updated, a detailed technology checklist was created, and the memorandum of understanding was modified to include a principal signature and review of the IT checklist. Even with these new communication efforts, some of our online participants have experienced technical issues at higher rates than those in the hybrid format. We are continuing to examine this issue to resolve technical difficulties. For the third year of the project we have instituted further steps to help teachers seamlessly implement the Mobile CSP curriculum and ensure student success, such as technology questions on the application, an infographic on IT requirements and a project orientation for participants that reinforces the required technology.

\section{CONCLUSION}

Overall, the data from this project suggest that the online Mobile CSP format has been successful, providing comparable results to the hybrid Mobile CSP format. We continue to refine our PD model based on survey data and project staff and master teacher feedback. In many cases, the data show little to no difference, and the results are primarily very positive for both PD formats (online and hybrid). We believe that our results suggest that careful and deliberate planning of online PD, rooted in evidence-based practices, can be successful providing a viable, flexible and scalable option for teachers to receive PD.

\section{ACKNOWLEDGMENTS}

We would like to thank the Mobile CSP hybrid team members, Pauline Lake and Chinma Uche, our grant evaluator, Lawrence Baldwin, and all the master teachers and participant teachers. This material is based upon work supported by the National Science Foundation under Grant Nos. CNS-1240841, CNS-1440947, and CNS-1547051 and by Google's CS4HS program.

\section{REFERENCES}

[1] Building an operating system for computer science: Landscape study. Retrieved from

http://outlier.uchicago.edu/computerscience/OS4CS/landscapestudy/

[2] Computer Science Teachers Association (CSTA), Association for Computing Machinery (ACM). (2013). Bugs in the system: Computer science teacher certification in the U.S. \{Report\}. Retrieved from http://csta.acm.org/ComputerScienceTeacherCertification/sub/CSTA BugsInTheSystem.pdf

[3] College Board. (2016). Providers of CSP Curricula and Pedagogical Support. Retrieved from https://advancesinap.collegeboard.org/stem/computer-scienceprinciples/curricula-pedagogical-support on January 15, 2017.

[4] Cuny, J. (2015). Transforming K-12 computing education: AP ${ }^{\circledR}$ computer science principles. ACM Inroads 6, 4 (November 2015), 58-59. DOI: https://doi.org/10.1145/2832916

[5] Darling-Hammond, L., Chung Wei, R., Andree, A., Richardson, N., \& Orphanos, S. (2009). Professional Learning in the Learning Profession. National Staff Development Council and The School Redesign Network at Stanford University. Retrieved from https:/edpolicy.stanford.edu/sites/default/files/publications/professio nal-learning-learning-profession-status-report-teacher-developmentus-and-abroad_0.pdf

[6] DuFour, R. (2004). What is a professional learning community? Educational Leadership 61 (8) 6-11 Retrieved from http://www.ascd.org/publications/educationalleadership/may04/vol61/num08/What-Is-a-Professional-LearningCommunity\%C2\%A2.aspx

[7] Garrison, D. R., Anderson, T., \& Archer, W. (2000). Critical inquiry in a text-based environment: Computer conferencing in higher education model. The Internet and Higher Education, 2(2-3), $87-$ 105.

[8] Google Inc. \& Gallup Inc. (2016). Trends in the State of Computer Science in U.S. K-12 Schools. Retrieved from http://goo.gl/j291E0

[9] Hardee, C., Duffin, M., \& PEER Associates. (2013). Five (+) guiding principles for professional development: Summary report, professional development literature review. Project Learning Tree, Washington, DC.

[10] Morelli, R., Uche, C., Lake, P., \& Baldwin, L. (2015). Analyzing Year One of a CS Principles PD Project. SIGCSE-2105 Proceedings of the 46th ACM Technical Symposium on Computer Science Education, pp 368-373. http://dl.acm.org/citation.cfm?doid=2676723.2677265.

[11] Tripp, T. and Rich, P. (2012). The influence of video analysis on the process of teacher change, Teaching and Teacher Education, Volume 28, Issue 5, July 2012, Pages 728-739, ISSN 0742-051X, http://dx.doi.org/10.1016/j.tate.2012.01.011.

[12] Wenger-Trayner, B., \& Wenger-Trayner, T. (2015). Introduction to communities of practice: A brief review of the concept and its uses. Retrieved from http://wenger-trayner.com/introduction-tocommunities-of-practice/ on January 14, 2015. 